\title{
A MEMÓRIA SOBRE O "PIONEIRO": COMO OS NOMES DAS RUAS E PRÉDIOS PÚBLICOS LEGITIMAM O DISCURSO DO "PIONEIRISMO"
}

\author{
THE MEMORY ABOUT THE "PIONEER" \\ HOW THE NAMES OF STREETS AND PUBLIC BUILDINGS LEGITIMATE \\ THE DISCOURSE OF "PIONEERISM"
}

Cássio Augusto Samogin Almeida Guilherme ${ }^{1}$

\begin{abstract}
RESUMO: O presente texto analisa os nomes de ruas e prédios públicos da cidade de Nova Londrina, localizada no extremo Noroeste do Paraná. Nosso objetivo é observar como a escolha deliberada de alguns nomes em detrimento de outros colabora na construção de uma memória local acerca do "pioneirismo" e dos "melhores políticos" locais. Nossa hipótese é que nesta escolha há um poder simbólico envolvido na manutenção da prática patrimonialista, muito comum nas pequenas cidades interioranas.
\end{abstract}

Palavras-chave: Pioneirismo. Poder simbólico. Discurso.

\begin{abstract}
This present article analyses the names of streets and public buildings of Nova Londrina, located in the Northwest region of Paraná. Our goal is to look how the deliberate choice of some names instead of others corroborates with the making of a local memory about the "pioneerism" and of the local "best politicians". Our hypothesis is that this choice has a symbolic power involving the maintenance of a patrimonialistic view of history, particularly common in small cities.
\end{abstract}

Keywords: Pioneering. Symbolic power. Discourse.

\footnotetext{
1 Mestre em História pela Universidade Estadual de Maringá (UEM). Professor da Faculdade Ingá/Uningá
} 


\section{Introdução:}

Os nomes que uma cidade dá para as suas ruas e prédios públicos podem dizer muito sobre o seu povo, ou pelo menos, sobre a parcela política da população que decide o nome das ruas. Prática comum desde a República Velha, nossos políticos tentam impor uma memória sobre si ou seus aliados aos cidadãos que governam. Em texto recente publicado na Revista Carta Capital, o filósofo Vladimir Safatle argumenta que "a maneira como a memória social configura os espaços públicos e marca os monumentos não é uma questão menor" (201, p. 33).

Segundo o filósofo, a simples escolha dos nomes dos logradouros públicos define os processos de transmissão do passado ou do presente às futuras gerações. No entanto, esta memória é imposta e "visa fornecer a narrativa edificante de que sempre fomos governados por 'grandes homens e mulheres'" (2013, p. 33). Tais práticas seriam dignas do folclórico personagem da dramaturgia Odorico Paraguaçu, e mostraria o "verdadeiro arcaísmo provinciano" (2013, p. 33) dos nossos políticos locais.

Assim, o presente texto tem por finalidade analisar os nomes das ruas e prédios públicos da pequena cidade de Nova Londrina, localizada no extremo Noroeste do Estado do Paraná e buscar nelas a construção deliberada de um discurso excludente sobre o "pioneiro" na cidade. Para tanto articulamos a bibliografia pertinente sobre o tema e produzida recentemente.

\section{O fenômeno do pioneirismo e a cidade de Nova Londrina-PR}

O processo de (re)ocupação da região Noroeste do Paraná como um todo contou com forte discurso ideológico para legitimá-lo. Segundo Lucio Tadeu Mota, quando o capital conquista novos espaços, "a sua história passa a ser recontada a partir da visão que os 
conquistadores têm de si" (2005:75). Neste sentido, foi criado pelo Estado e também pelas Companhias Imobiliárias todo um discurso oficial do "vazio demográfico", da "Nova Canaã", da não participação estatal no processo e principalmente do "pioneirismo".

Nas palavras de Nelson Tomazi (1999, p. 74), na região se criou "uma 'galeria' de personagens intitulados 'pioneiros', procurando-se, assim, enaltecer a figura de determinadas pessoas e colocar na ação de alguns indivíduos a força da 'pujança regional'". Continua o autor, argumentando no sentido de que algumas pessoas eram elevadas à categoria de exemplo maior, que deveriam ser veneradas como se fossem os emissários do progresso, mas, ao mesmo tempo, esse "discurso oficial" silenciava-se sobre os demais partícipes do mesmo processo. Tal fato gerou "uma fantasmagoria para silenciar e se fazer esquecer todos aqueles que realmente derrubaram a mata e construíram a cidade" (TOMAZI, 1999, p. 76). Conforme texto do jornalista João Antônio Corrêa Júnior:

Na região norteparanaense houve muita violência ligada à ocupação de suas glebas Muito sangue jorrou, muitos barracos foram queimados até com famílias inteiras sacrificadas à sanha bestial de poderosas oligarquias que estabeleciam feudos, incontidos na desenfreada ambição de Iucro fácil e volumoso. (...) Existem fortunas feitas à custa do sacrifício de vidas nessas colonizações. (CORRÊA JR, 1991, p. 29)

Em outras palavras, há na região uma leva de pessoas que "deram certo", "venceram" e conseguiram ficar ricos, que ainda hoje são considerados os "pioneiros" da cidade, muitos dos quais têm seus nomes eternizados nas ruas dos municípios. Nesse sentido, é reveladora da situação vivida pelos trabalhadores braçais e digna de comoção a fala do Senhor Jair Rezende, quando perguntado se ele, seus pais e irmãos trabalhavam "para aqueles que se chamavam pioneiros", bem como se o mesmo teria sido um "pioneiro". Eis as respostas: 
Isso, exatamente. Então nós trabalhava para esse povo. (...) A nossa vida nós levava era na roça. Nós plantava, colhia, trabalhava pros outros, colhi café, colhia algodão, amendoim. (...) Eu fui um dos pioneiros. Eu, meu pai foi um pioneiro, meus irmãos foram pioneiros. Mas os pioneiros de Nova Londrina, que eles contam como pioneiros, são pessoas que teve dinheiro, são pessoas políticas. Então pra eles, os pioneiros são esses. Mas eles estão enganados, porque eles não foram pioneiros.

Sobre esse tema, recorremos à dissertação de mestrado, defendida junto à Pontifícia Universitária Católica, por Maurílio Rompatto (1995, p. 121-124), em que é analisada a questão do pioneirismo na cidade de Nova Aurora, no Estado do Paraná. A tentativa de se eleger alguns "pioneiros" em detrimento de outros possui vários objetivos, por nós aqui assim esquematizados: 01 "ocultar as diferenças, as desigualdades e os conflitos sociais que marcaram a história da colonização da terra na região"; 02- "o critério usado é a propriedade, base da sociedade herdada pelas gerações presentes e a riqueza advinda do trabalho"; 03 - "o pioneiro é usado pela elite como suporte para sustentar seu discurso dominante"; 04- procura-se, "ao mesmo tempo, excluir as falas dos velhos pioneiros que foram posseiros bem como sua narrativa sobre a Colonização da região". Em suma, há uma escolha deliberada de quem será considerado "pioneiro". Essa escolha é parte do discurso das classes dominantes, a fim de reconstruir o passado segundo um olhar de classe. Inclusive, no Projeto Memória², muitos entrevistados da região corroboram este discurso (ROMPATTO, 2012, p. 39). Em Nova Londrina, há a mesma situação.

A construção histórica do "pioneirismo" pode ser observada também no Hino de Nova Londrina, que, em certo verso, diz: "amor e esperança, coragem e ação/ arrojo e segurança são marcas do teu chão/ teu rubro sobre o seio traçado com ardorl ao sangue do pioneiro e a mão do criador" ${ }^{3}$.

\footnotetext{
2 Projeto desenvolvido junto à Faculdade Estadual de Educação, Ciências e Letras de Paranavaí Fafipa e coordenado pelo Professor Doutor Maurílio Rompatto.

${ }^{3}$ Letra de Vera Vargas e melodia de Sebastião Lima.
} 
Esta falsa memória sobre o pioneirismo é tão forte nas cidades da região que o livro do professor novalondrinense, Osmar Soares Fernandes, logo em sua apresentação exalta "a coragem dos seus fundadores, a bravura dos seus pioneiros" (2010, p. 5) e algumas páginas a seguir traz uma lista de "pioneiros de Nova Londrina" em ordem alfabética (2010, p. 21). Ou seja, fica clara a necessidade de selecionar alguns nomes e sobrenomes para fazerem parte do rol de "bravos e corajosos fundadores da cidade". O livro é mais um, dos tantos que não fazem o debate crítico sobre o discurso "pioneirista" na região Noroeste do Paraná.

O fluxo migratório para a cidade de Nova Londrina foi bastante variado. Uns poucos paulistas e mineiros vieram estender suas fronteiras agrícolas, muitos deles descendentes de imigrantes europeus ou japoneses, muitos nordestinos, vítimas da seca e da miséria chegavam a busca de trabalho na derrubada da mata e plantio do café, mas a Imobiliária Nova Londrina Ltda., dona das terras que eram vendidas aos "pioneiros", "deu total referência a formar, na nascente cidade, uma colonização com migrantes sulistas" (GUILHERME, 2012: 35), havia inclusive um veículo da Imobiliária que buscava pessoas no Sul do país e corretores percorriam aquela região vendendo os lotes. Tanto é forte a presença sulista na cidade que um Centro de Tradições Gaúchas (CTG) foi criado e funciona até os dias de hoje.

\section{As ruas, prédios públicos e os "homenageados":}

Atualmente, segundo dados do $\mathrm{IBGE}^{4}$, a cidade de Nova Londrina possui hoje pouco mais de 13 mil habitantes e possui como base de sua economia as indústrias agrícolas lá instaladas, principalmente para beneficiamento da mandioca, cana-de-açúcar e carne bovina. O mapa

\footnotetext{
${ }^{4}$ Dados do IBGE no site: http://www.ibge.gov.br/cidadesat/painel/painel.php?codmun=411710
} 
da cidade que utilizamos como referência para analisarmos os nomes das ruas é o contido no site de buscas Google ${ }^{5}$.

Nem todas as ruas da cidade possuem nomes de pessoas. Muitas delas são homenagens às santidades católicas, o que demonstra o forte caráter religioso da sua colonização, até os dias atuais (GUILHERME, 2012, p. 38), inclusive, o primeiro pároco da cidade, Padre Ernesto Beviláqua, tem seu nome imortalizado em uma rua. Além disso, uma quantidade grande de ruas tem nomes em homenagens às cidades paranaenses ou outras capitais de Estados da federação. Inclusive, estas ruas com nomes de cidade costumam ter os nomes trocados para então homenagearem políticos ou pioneiros recém-falecidos. Exemplo recente é a Avenida Paranaguá que passou a ser Egídio Daniel Kerntopf, um dos "pioneiros" da cidade e parente de ex-vereador e a avenida Paraná que passou a homenagear o exvereador e ex-prefeito João Fernandes de Almeida. Por fim, é possível observar no mapa que muitas ruas e travessas localizadas nos extremos da cidade ainda contam com nomes de letras ou números.

Excetuando estes casos, analisamos 36 nomes de ruas e os confrontamos com a "lista de pioneiros" contida no livro do professor Osmar Soares Fernandes (2010), bem como as atas dos resultados finais das eleições municipais ao longo de toda a história da cidade ${ }^{6}$, para encontrarmos os políticos ou parentes de políticos que foram homenageados nas ruas de Nova Londrina. De todos os 36 nomes, 24 deles puderam ser encontrados nas listas dos "pioneiros" ou então nas listas das eleições municipais, quando não em ambos os casos, o que dá um total de $66 \%$ das ruas da cidade.

Como nos referimos acima, o livro acrítico do professor Osmar Soares Fernandes traz logo em seu começo um rol com 210 nomes de "Pioneiros de Nova Londrina" (2010, p. 21). Como ele chegou a tais

\footnotetext{
5 Disponível no site do Google em: https://maps.google.com.br/maps?q=nova+londrina + maps\&ie=UTF8\&hq =\&hnear $=0 \times 948 d 90 b b d 8 b 00 e 2 d: 0 x f b 5205 f d 6 f 191597$, Nova +Londrina+$+P R \& g l=b r \& e i=j P X \_U c O f J J L C 9 g T-r Y H o A Q \& v e d=0 C D E Q 8 g E w A A$

6 Disponível no site do TRE: http://www.tre-pr.jus.br/eleicoes/resultados/resultados-de-eleicoesmunicipais-tre-pr
} 
nomes em detrimento de outros, não saberemos, uma vez que seu livro não possui referências bibliográficas ou referência às fontes documentais, entrevistas etc. Assim, ficamos com a impressão de que houve uma escolha deliberada que beneficia alguns em detrimento de outros "pioneiros". Aliás, ao final do seu rol, há a "mea-culpa" do autor: "Que os demais pioneiros sintam-se homenageados com este histórico" (2010, p. 23).

De todas as 36 ruas com nomes de pessoas da cidade, 16 delas são homenagens a "pioneiros" novalondrinenses constantes na lista citada acima, o que equivale a $44 \%$ delas. Destes 16 "pioneiros", sete também foram políticos ou parentes de políticos em algum momento da história da cidade. Para ficarmos em alguns exemplos de "pioneiros": Antonio Ormeneze, Fioravante Montanher, João Venâncio da Rocha, Luiz Guilherme e Massato Morimatsu.

Da mesma lista de ruas com nomes de pessoas na cidade, 13 delas homenageiam políticos ou parentes de políticos de Nova Londrina, o que representa $36 \%$ das ruas. Destes 13 nomes, cinco deles homenageiam parentes de políticos locais: Antonio Grendene é pai do ex-prefeito Olivier Grendene, figurão da política local ao longo de vários anos (GUILHERME, 2012); Guilhermino Augusto é pai do exvereador e vice-prefeito Arnaldo Augusto; José dos Santos Pires é pai do ex-vereador de três legislaturas, João Celestino Pires; Severino Pedro Troian é pai do ex-prefeito por três oportunidades, Arlindo Adelino Troian, que também já foi deputado estadual e pai do também ex-prefeito Waldir José Troian e Egídio Kerntopf é pai do ex-vereador Euclides Kerntopf.

Três casos são de pessoas que além de terem sido políticos locais, outros parentes seus também o foram em algum momento da história local. Luiz Paviani foi vereador na legislatura 1960-1964 e seu parente Sady Paviani, prefeito municipal entre 1973-1977; Mário Pilegi foi vereador entre 1964-1968 e seu filho Mário Pilegi Júnior vereador por três legislaturas; João Fernandes de Almeida foi quatro vezes 
vereador e também prefeito municipal entre 1997-2000 e seu sobrinho Aguinaldo Fernandes de Lima vereador nestes mesmos anos.

A lista de nomes de ruas com políticos novalondrinenses possui nove casos. Alcindo Pinto de Arruda foi secretário municipal entre 1973-1977; Edmundo Grabowski foi sub-prefeito entre 1953-1956 quando a cidade ainda era distrito de Paranavaí; Manoel Bono Rodrigues, vereador entre 1969-73; Raimundo de Oliveira, vereador entre 1969-1973; Teikin Tina, vereador entre 1969-1973; Valdir Santir vereador na legislatura 1973-1977. Além destes seis, mais os casos dos já mencionados acima Luiz Paviani, Mário Pilegi e João Fernandes de Almeida.

No que diz respeito aos prédios públicos, muitos também homenageiam "pioneiros" e/ou políticos locais. Levantamos um total de 11 deles. O conjunto habitacional Sauer Salum é uma referência ao médico e ex-interventor federal entre 1969 e 1971, pela injusta cassação do prefeito Halim Maaraoui, naquele ano, sob acusação de subversão, posteriormente absolvido pela justiça militar que entendeu se tratar de mera "politicalha interiorana" arquitetada e executada pelos adversários políticos de Halim (GUILHERME, 2012). O recentemente construído Centro de Geração de Renda homenageia o ex-vereador por três legislaturas seguidas, João Celestino Pires.

Mas as maiores referências estão em prédios públicos da área cultural da cidade. O Colégio Ary João Dresch é a referência a um dos "pioneiros" da cidade e parente do sócio da Imobiliária Nova Londrina Ltda., colonizadora da cidade, Silvestre Dresch. Outro sócio da Imobiliária e "pioneiro", Senhor Armando Chiamulera tem seu nome eternizado na recém-construída Biblioteca Cidadã. O Ginásio de Esportes homenageia o também "pioneiro" Arno Ravache. O Estádio Municipal leva o nome do "pioneiro" e segundo a memória popular, doador do terreno onde o mesmo foi construído, João Venâncio da Rocha.

A primeira professora e uma das "pioneiras" da cidade (GUILHERME, 2010), Senhora Ondina Giacobbo é justamente 
homenageada na Super Creche Infantil construída recentemente. Também o primeiro prefeito municipal, Senhor Avelino Antonio Colla tem sua memória eternizada no Anfiteatro Municipal.

Casos que nos chamam a atenção são as deferências à família Troian. Se nos anos 1960-70 a política novalondrinense girou em torno da pessoa do médico Olivier Grendene (GUILHERME, 2012), nas décadas seguintes até os dias atuais, a política local teve a família Troian como hegemônica na cidade. Quatro irmãos merecem destaque nesta atuação.

Arlindo Adelino Troian foi eleito vereador pela primeira vez na legislatura 1977-1983 com 662 votos, recorde histórico e mantido até os dias atuais. Para se ter uma ideia, o segundo colocado naquela eleição obteve 177 votos e o mais votado na eleição de 2012, o vereador José Valter Sampaio conquistou 447 eleitores. Naquela legislatura, Arlindo Troian ainda foi presidente da câmara municipal por dois biênios.

Tal atuação o credenciou a vencer a eleição seguinte para prefeito municipal, pelo Partido Democrático Social (PDS), antiga Arena, de sustentação ao Regime Civil-Militar ditatorial. Arlindo Troian administrou Nova Londrina entre os anos 1983-1988 e contou com sua irmã, Lurdes Troian, como secretária de Assistência Social. Ao final de seu mandato, ainda mandou publicar uma revista intitulada "Nova Londrina 30 anos". Essa revista, além de servir como meio de propaganda dos seus "anos de trabalho pela comunidade" (1986: 35), aproveitava a festividade de 30 anos de emancipação política do município, para ser uma espécie de "história oficial" da cidade, registrando "o trabalho, a coragem, a dedicação e o heroísmo (...) de seus Fundadores, com a coragem e o destemor de seus Pioneiros" (1986:03).

A eleição seguinte na cidade foi vencida pelo então seu aliado político, Idreno Gregório, como candidato único. No período de 19901994, Arlindo Troian exercia, em Curitiba, a função de Deputado Estadual pelo Partido da Reconstrução Nacional (PRN) o mesmo do ex- 
presidente Fernando Collor. Na eleição seguinte, Arlindo Troian não conseguiu se reeleger Deputado, porém sua família manteve a hegemonia local, pois seu irmão Waldir José Troian se tronou prefeito de Nova Londrina entre os anos 1993-1996.

Por uma administração conturbada com salários atrasados dos servidores municipais, a oposição venceu a eleição seguinte por apenas 14 votos de diferença. Foi eleito João Fernandes de Almeida, já citado acima contra o candidato troianista, o ex-prefeito Idreno Gregório.

O controle político local foi recuperado pela família Troian nas duas eleições seguintes. Arlindo Troian foi eleito prefeito municipal para o período 2001-2004 e reeleito para o período 2005-2008, desta vez pelo Partido do Movimento Democrático Brasileiro (PMDB). Nestes anos, seus irmãos ocuparam importantes cargos na administração pública. Lurdes Troian foi diretora do Centro de Educação Infantil Irmão Caçula; Alcides Troian foi chefe de gabinete ao mesmo tempo em que respondia pela Secretaria de Finanças e o ex-prefeito Waldir Troian, Secretário de Saúde em Nova Londrina. Embora alguns juristas entendam que o art. 37 da Constituição Federal já contemple a proibição ao nepotismo, apenas a partir de 2005 o Conselho Nacional de Justiça incitou o debate que culminou com o Decreto 7.203 de 2010 que definitivamente regulamenta a questão. Nas eleições seguintes, a família Troian mais uma vez sofreu revezes nas eleições ao executivo municipal, muito embora atualmente, Waldir Troian seja vereador na cidade.

Todo este resumo da vida política do grupo troianista se fez necessário para analisarmos os logradouros públicos que homenageiam a família. Além da rua com o nome do patriarca Severino Troian, já citada acima, o mesmo empresta seu nome para um conjunto habitacional logo na entrada da cidade. A matriarca, Dozolina Troian, também é homenageada em uma creche na cidade.

Apesar disso, o fato mais estranho, absurdo e ilegal foi o exprefeito Arlindo Troian em nomear o Terminal Rodoviário construído na sua gestão 1983-1988 com o próprio nome. Para que fique claro, 
Arlindo Troian homenageou a si próprio nomeando a Rodoviária local com o nome de Arlindo Troian. Tal ato é ilegal conforme artigo 37 da Constituição Federal. No caso de Nova Londrina, este fato é significativo da atuação provinciana e personalista de boa parte dos políticos locais.

Além disso, a cidade conta com várias ruas que homenageiam "pioneiros" descentes de japoneses. Por exemplo, as ruas Itio Kondo, Massato Morimatsu, Kissao Numazawa. Teikin Tina e Tokushi Kondo, o que demonstra a força cultural e econômica da colônia nipônica na cidade, muito embora eleitoralmente esta força nunca fosse bem capitalizada.

A hegemonia Católica em Nova Londrina pode ser observada pelos nomes das ruas de um dos bairros periféricos do município. Santidades do catolicismo como Santa Amélia, Bernadete, Catarina, Cecília, Felicidade, Mariana e Rita de Cássia fazem do fenômeno religioso católico um importante instrumento de luta ideológica no bairro.

Interessante notar que algumas poucas figuras históricas são lembradas nos nomes das ruas da cidade. O ex-presidente Juscelino Kubitschek é a figura mais próxima do nosso tempo histórico. As demais tiveram sua atuação no período que denominamos de Brasil Império: Princesa Isabel, que assinou a Lei Áurea; José Bonifácio, um dos líderes civis no processo de Independência do Brasil; General Osório, líder militar da Guerra do Paraguai; Duque de Caxias, também líder militar da revolução Farroupilha e Dom Pedro II, último imperador do Brasil. Além destes personagens históricos do Brasil, há uma exceção inusitada: a rua Rainha Elizabeth, importante figura da história mundial enquanto rainha da Inglaterra no século XVI.

Por fim, mas não menos importante, muitas ruas de Nova Londrina fazem referências a outros Estados do Brasil e cidades do Paraná. Salientamos que tais ruas são as de preferência para serem renomeadas pelos vereadores locais em busca da perpetuação de uma memória política e "pioneira" no município. 


\title{
Considerações Finais
}

O professor Reginaldo Dias assim se manifestou sobre o tema ao fazer uma pesquisa análoga sobre a cidade de Maringá:

\begin{abstract}
A prática de nomear ruas, quase sempre identificada como distorção do trabalho dos vereadores, é atividade menos inocente do que se costuma supor. Um olhar atento constata que esse processo é caracterizado pelo esforço de perenização da memória de personagens e fatos da história nacional ou local. Trata-se de recorrente forma de reprodução e perpetuação da chamada história oficial, baseada no culto à genealogia da nação e edificação do Estado nacional, assim como aos fatos e personagens correspondentes. (2000, p. 103)
\end{abstract}

Diante do aqui trabalhado, entendemos que a escolha deliberada de alguns nomes em detrimento de outros para os logradouros públicos de Nova Londrina, constituem-se em uma importante ferramenta simbólica para a construção da memória política do novalondrinense. "O poder simbólico é um poder de construção da realidade que tende a estabelecer uma ordem gnoseológica" (BOURDIEU, 2011, p. 09).

Assim, há o efeito ideológico por parte da classe dominante local e a escolha de alguns nomes para serem celebrados como os legítimos "pioneiros" ou então como os "melhores políticos", serve para criar uma:

Integração fictícia da sociedade no seu conjunto, portanto, à desmobilização (falsa consciência) das classes dominadas; para a legitimação da ordem estabelecida por meio do estabelecimento das distinções (hierarquias) e para a legitimação dessas distinções. (...) É enquanto instrumentos estruturados e estruturantes de comunicação e de conhecimento que os 'sistemas simbólicos' cumprem a sua função política de instrumentos de imposição ou de legitimação da dominação, que contribuem para assegurar a dominação de uma classe sobre outra (violência simbólica) dando o reforço da sua própria força às relações de força que fundamentam e contribuindo assim, segundo a expressão de Weber, para a 'dominação dos dominados'". (BOURDIEU, 2011, p. 10-11) 
Como já nos referimos em outra pesquisa (GUILHERME, 2012), ao analisar a injusta cassação do prefeito Halim Maaraoui, acusado por seus adversários políticos locais de subversivo, quando na verdade estavam indignados com a perda do mando político na cidade, o sentimento patrimonialista por parte do grupo de "pioneiros" também pode ser encontrado na escolha dos nomes de logradouros públicos. Afinal, como sugere Raymundo Faoro:

A comunidade política conduz, comanda, supervisiona os negócios, como negócios privados seus, na origem, como negócios públicos depois, em linhas que se demarcam gradualmente. (...) Dessa realidade se projeta, em florescimento natural, a forma de poder, institucionalizada num tipo de domínio: o patrimonialismo, cuja legitimidade assenta no tradicionalismo - assim é porque sempre foi (FAORO, 1995, p. 733 ).

No caso de Nova Londrina, esta elite política utiliza de suas funções públicas para construir simbolicamente, através dos nomes de ruas e prédios públicos, uma memória sobre o "pioneirismo" e os "melhores políticos" e seus parentes no município. O público e o privado se confundem desde o início do processo de "colonização" da cidade e os resquícios de patrimonialismo e culto à personalidade podem ser observados ainda nos dia atuais.

\section{Referências}

ARQUIVO do Projeto Memória do Noroeste do Paraná - Acervo de Nova Londrina, entrevista de número 07, com Jair Rezende, realizada por Cássio Augusto S.A. Guilherme. Nova Londrina-PR, 30 maio de 2009.

BOURDIEU, P. O poder simbólico. Rio de Janeiro: Bertrand Brasil, 2011.

CORRÊA JR. J. A. O Trem de Ferro. Maringá: Editora 5 de abril, 1991.

DIAS, R. B. A história além das placas: os nomes de ruas de Maringá (PR) e a memória histórica. História \& Ensino, v.6. Universidade 
Estadual de Londrina: Londrina, 2000. Disponível em: http://www.uel.br/revistas/uel/index.php/histensino/article/view/1239 $3 / 10853$

FAORO, R. Os Donos do Poder. v. 2. São Paulo: Globo, 1995.

FERNANDES, O. S. Nova Londrina rainha do noroeste: 60 anos de história. Cascavel: Ed do Autor, 2010.

GUILHERME, C. A. S. A. A Ditadura Civil-Militar e a "politicalha interiorana": o caso Halim Maaraoui em Nova Londrina-PR (1969). Curitiba: Editora CRV, 2012.

MOTA, L. T. História do Paraná: ocupação humana e relações interculturais. Maringá: EDUEM, 2005.

NOVA LONDRINA: 30 ANOS. Editor Euclides Bogoni. Paranavaí, 1986.

ROMPATTO, M. O processo de (re)ocupação do noroeste do Paraná, Microrregião de Paranavaí, na história e na memória de seus moradores. In ROMPATTO, M. História e memória da colonização do noroeste do Paraná: os casos de Paranavaí, Nova Londrina e Loanda. Maringá: Massoni, 2012.

ROMATTO, M. Piquiri: "O vale esquecido". Memórias da luta pela terra em Nova Aurora, Paraná, desde os anos 1950. Dissertação de Mestrado Pontifícia Universitária Católica, São Paulo, 1995.

SAFATLE, V. A imposição da memória. Carta Capital, n. 752, $12 / 06 / 2013$.

TOMAZI, N. D. Construções e silêncios sobre a (re)ocupação da região norte do estado do Paraná. In DIAS, R. B.; GONÇALVES, J. H. R. (Org.). Maringá e o Norte do Paraná. Estudos de história regional. Maringá:

Eduem, 1999. 